\title{
The Sport Mental Training Questionnaire: Development and Validation
}

\author{
Maciej Behnke $^{1}$ (D) Maciej Tomczak ${ }^{2}$ - Lukasz D. Kaczmarek ${ }^{1}$ Marek Komar $^{3}$ • \\ Jacek Gracz ${ }^{2}$
}

Published online: 23 June 2017

(C) The Author(s) 2017. This article is an open access publication

\begin{abstract}
Research in sports psychology has revealed that mental training is essential in the development of successful athletes. This project, comprised of five studies (a total of $N=2015)$ resulted in a novel approach towards the measurement of mental skills in sport. In Study $1(N=797)$ and Study $2(N=405)$ we used principal component analysis to identify and confirm the structure of a wide range of identified sport mental skills. Study $3(N=429)$ and Study $5(N=330)$ confirmed factorial structure of Polish and English versions. Study 4 documented how both versions of the scale were developed, and how these two versions converge supporting their cross-cultural validity. The final version contains 20 items grouped into 5 subscales (foundational skills,
\end{abstract}

Electronic supplementary material The online version of this article (doi:10.1007/s12144-017-9629-1) contains supplementary material, which is available to authorized users.

Maciej Behnke

macbeh@amu.edu.pl

Maciej Tomczak

mtomczak@awf.poznan.pl

Lukasz D. Kaczmarek

1kacz1@gmail.com

Marek Komar

marek@ flowperformancepsych.com

Jacek Gracz

gracz@awf.poznan.pl

1 Institute of Psychology, Adam Mickiewicz University, 89 Szamarzewskiego Str, 60-658 Poznań, Poland

2 Department of Psychology, University School of Physical Education Poznan, 27/39 Krolowej Jadwigii Str, 61-871 Poznań, Poland

3 Flow Performance, Edmonton, AB, Canada performance skills, interpersonal skills, self-talk and mental imagery). The Sport Mental Training Questionnaire is a reliable and valid brief questionnaire that will facilitate psychological evaluation of mental preparation among athletes.

Keywords Mental skills · Sport psychology · Psychological assessment · Questionnaire

\section{Introduction}

Most sport coaches observe that the victory against an opponent with similar physical abilities depends in ca. $50 \%$ on psychological preparation (Weinberg and Gould 2015). Research in sports psychology has revealed that mental training facilitates successful performance and enhances athletes' personal well-being (Vealey 2007). Therefore most athletes make additional mental efforts to enhance their performance as a supplement to physical training. Mental training interventions are used to facilitate specific positive outcomes such as passes efficacy in soccer (Thelwell et al. 2010) or forehand drive efficacy in tennis (Hatzigeorgiadis et al. 2008).

Mental training has been founded on the assumption that psychological factors enhance or inhibit physical performance (Vealey 2007). For instance, excessive levels of psychological stress disturb cognitive focus on the task and increase the focus on the self resulting in a lower level of sport efficacy (Hill et al. 2010; Mesagno et al. 2012). Therefore regulation of excessive stress and negative emotions promotes better performance (Anshel and Anderson 2002; Lane et al. 2011). This is the general theoretical rationale for the use of mental training that provides athletes with new skills that are effective in building a stronger mindset, e.g., with new mental resources that reduce negative states (e.g., distress through positive self- 
talk (Hatzigeorgiadis et al. 2009) or enhance positive states (e.g., enhanced focus relaxation routines) (Lutz et al. 2009).

Several components of mental training have been validated, e.g., mental imagery techniques (Gentili et al. 2010), selftalk techniques (Hatzigeorgiadis et al. 2004), and preperformance routines (Velentzas et al. 2011). Yet a list of active mental ingredients in these interventions as well as their structure have not been established. Research within the psychological interventions theory has indicated that numerous components of interventions used in applied settings can be reduced to a lower number of components that are sufficient to explain the intervention outcomes (Michie et al. 2013). This is an important aspect of applied studies, because such reduction helps to separate active ingredients (that generate desirable outcomes) from inactive intervention ingredients (that are irrelevant to outcomes). In statistical terms, it is important to test whether each identified ingredient is independent (first-order factors), and secondly, whether specific ingredients group together (second-order factors). From an applied perspective, such structure testing is important to examine whether levels of specific skills are likely to depend on other skills or techniques. Furthermore, there are conceptual inconsistencies within the literature regarding the meaning of mental skills and mental techniques that are often used interchangeably (Hardy et al. 2010). However, theorists suggest that these terms refer to two groups of mental training elements (Birrer et al. 2012; Vealey 2007). A mental skill is the learned capacity or ability to carry out a specific training task (goal), e.g., attentional focus or coping with stress. Whereas a technique is a specific procedure used to achieve mental training goals, e.g., mental imagery or self-talk. This distinction between skills and techniques is important conceptually and it is also important for the applied science because athletes and coaches need to set adequate goals and use efficacious techniques to achieve these goals. From the research perspective, it is vital to further identify what key components are uniquely related to performance success in order to improve assessment and interventions throughout mental training for athletes.

One of the models that account for the differentiation between mental skills and mental techniques is a comprehensive model of mental training developed by Vealey (2007). This model suggests that mental training is nested within several broader contexts. From the most general perspective, mental training is nested within a specific cultural context of society. Within this broad societal context, specific individual training philosophy or approach (e.g., educational vs clinical or program-centered vs athlete-centered approach) proposed by the coach or training consultant determines the choice of a preferred model of training. Models of training (e.g., self regulatory models or cognitive-behavioral models) are overarching thematic frameworks that comprise a functional background for more specific interventions. Finally, within this broad contexts specific techniques (eg. imagery, self-talk) are used in sport psychology interventions to influence the development of targeted mental skills such as performance skills (eg. emotion regulation) or foundation skills (eg. selfconfidence), within well planned and adjusted to physical preparation implementation model.

Noteworthy, this model emphasizes the need for crosscultural research in sports psychology in the pursuit of high efficacy of mental training intervention. This is likely to facilitate cross-cultural research that is currently sparse and still needed in sports psychology after decades of calling for more systematic work on culture in sport (Duda and Allison 1990).

\section{Mental Training Assessment}

Psychological assessment in sports identifies psychological factors that enhance successful performance (Hardy et al. 2010). As presented in Table 1, several instruments have been created to measure personality constructs related to sports outcomes (Tutko et al. 1969; Nideffer 1976), general sport-related behaviours (Durand-Bush et al. 2001; Hardy et al. 2010; Loehr 1986; Smith et al. 1995; Thomas et al. 1999), specific mental skills (Williams and Cumming 2011; Zourbanos et al. 2009), or target specific disciplines (Albrecht and Feltz 1987; McAuley 1985). As with all psychometric questionnaires, it is essential to meet methodological standards such as established construct validity and reliability that contribute to the utility of these instruments (Tkachuk et al. 2003; Beckmann and Kellmann 2003). Given the abundance of present perspectives on the measurement of mental training components, it is imperative to perform integrative work that is likely to improve efficiency in psychometric measurements. For instance, using shorter questionnaires that address only the most important components make repeated measurements less burdensome (and thus more likely to occur). It may facilitate better tracking of changes in training effects. Secondly, a questionnaire with the most robust components which are universal across multiple sport disciplines may be more useful at early stages of mental training, during group assessments, in pre-screening, or in situations when the time resources of a coach are limited. Such integrative analyses are also likely to corroborate theoretical unity between different approaches present in the literature.

The focus of the present research project is on the development of a brief integrative tool that assesses viable components in mental training. Given a dynamic character of the sport domain, the most valuable measurement tool should be ecologically valid and able to assess current state of mental preparation of athletes in a relatively short time (e.g., several minutes). In line with these objectives, we focused on creating a brief questionnaire targeting mental training that could be used in the sport field. Additionally, we followed theoretical suggestion that mental training questionnaires should account 


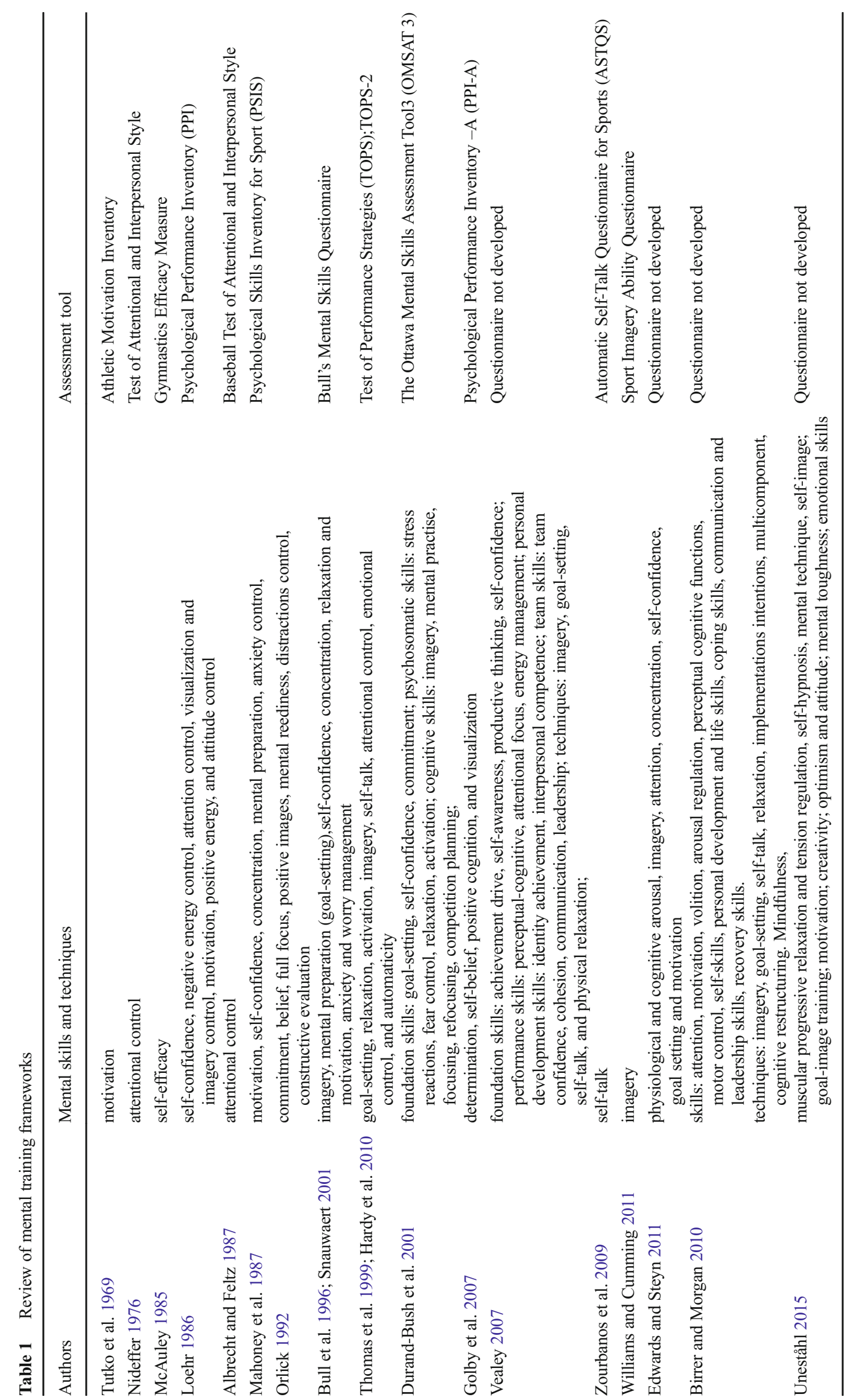


for distinctions between skills and techniques (Birrer et al. 2012; Vealey 2007).

Our questionnaire development process followed a recommendation that testing the reliability and validity of measures should be based on four stages (Netemeyer et al. 2003). Psychometric work should begin with the definition of the construct and content domain that would serve as the basis for the generated items pool. In study 1 we examined the structure of the questionnaire by principal component analysis (PCA). As a step toward content validity, six experts judged the reduced item pool. In Study 2 we examined the factor structure identified in the study 1 by PCA. Then we used Structural Equation Modelling (SEM) to validate findings from Study 2. Next, we developed the English version of the instrument. Finally, we used SEM to validate the instrument for international athletes.

\section{Study 1}

In line with the four-stages approach towards development of psychometric instruments (Netemeyer et al. 2003) our first aim was to define construct and content domain of mental training, generate an items pool, and examine the structure of the resulting questionnaire.

\section{Material and Methods}

\section{Participants}

Participants were 797 athletes who completed questionnaires in groups of 10-20 individuals $(N=421)$ recruited from local sport clubs and university students from the Faculty of Physical Education, or via a web-based survey $(N=376)$ (For details, see Table 2). Following suggestions from Tabachnick and Fidell (2007) that 10:1 ratio would be suitable for PCA, the criterion was met with the total of 797 cases. Written informed consent was obtained from each participant.

\section{Measures}

Baseline Information Participants reported their age, gender, sport played, competitive level (recreational, club, national, international), duration of participation in sport, duration of weekly physicaland mental training, and mental preparation efficacy beliefs, i.e.,to what extent mental preparation helps them achieve the best possible result during the competition in their discipline (using a rating scale 0-100\%).

Mental Training Using Sport Mental Training Questionnaire (SMTQ) participants reported their mental training routines. This was a66-item inventory which yielded an overall mental training score as well as scores for the 4 subscales of foundational skills, performance skills, personal development skills, and mental techniques. Participants responded using a 5-point Likert scale ( 1 = "strongly disagree", 5 = "strongly agree).

\section{Procedure}

Given the number of already existing assessment tools and available theoretical propositions targeted salient mental skills and techniques (Table 1), we explored their structures and conceptualized our questionnaire on the basis of Vealey's (2007) framework. Based on the source materials (e.g., quotes) available in qualitative studies (Gould et al. 2002; Gould et al. 1999) and items from measures of mental training (Table, 1), new items were developed in line with guidelines for items wording. Each item was worded so that athletes of 14 years of age and older would understand it. Furthermore, two sport psychologists (the second and fourth author of this paper) reduced the initial pool of 84 items to 66 items excluding redundant or ambiguous items.

Based on the theoretical framework by Vealey (2007), the items were grouped into two conceptually different subscales: mental skills (47 items) and mental techniques (19 items). The disproportion between the number of items in each category results from the model that accounts for thirteen basic mental skills (e.g., attentional focus) and four basic mental techniques (e.g., self-talk). This produced the initial pool of items in line with the general rule that there should be at least three items for one latent factor (Worthington and Whittaker 2006). Furthermore, based on the qualitative content analysis of the items we discussed the groups of similar items until a consensus was reached. This provided a mental skills scale that comprised three subscales: foundational skills (i.e., intrapersonal resources that are necessary to achieve success in sport), performance skills (i.e., mental abilities critical to the execution of specific physical skills during sport performance), and personal development skills (i.e., significant maturational markers of personal development which allow for high psychological functioning through clarity of self-concept, feelings of well-being, and a sense of relatedness to others). Mental techniques were reflected by items accounting for goal-setting, relaxation techniques, mental imagery, self-talk, and preparatory routines. Furthermore, to ensure that the tool is discipline-independent, we excluded skills that were exclusive to team sport disciplines (e.g., team confidence).

The reduced item pool was sent to six experts in mental training in sport: sport psychologists and sport psychology scholars. Each expert (a sport psychologist) received the definitions of the four factors and a table with the items pool. Based upon the procedure from prior studies (Dunn et al. 1999), the experts identified the subscale to which each item corresponded most strongly, or indicated that an item did not correspond to any subscale substantially. Additionally, experts 
Table 2 Participant characteristics for Studies 1 to 5

\begin{tabular}{|c|c|c|c|c|c|c|c|}
\hline & \multicolumn{7}{|l|}{ Study } \\
\hline & 1 & 2 & 3 & & 4 & 5 & \\
\hline & & & $\mathrm{T} 1$ & $\mathrm{~T} 2$ & & $\mathrm{~T} 1$ & $\mathrm{~T} 2$ \\
\hline$N$ & 797 & 405 & 429 & 112 & 54 & 330 & 40 \\
\hline Paper/web-based & $421 / 376$ & $250 / 155$ & $220 / 209$ & $74 / 38$ & $54 / 0$ & $162 / 168$ & 40 \\
\hline Female & 289 & 195 & 173 & 43 & 45 & 172 & 18 \\
\hline Male & 508 & 210 & 256 & 69 & 9 & 157 & 22 \\
\hline Age (years) & $22,72(7.17)$ & $23.00(5.19)$ & $23,14(6.06)$ & $22,55(5.69)$ & $19,17(2.82)$ & $24,25(7.88)$ & $26,05(9.18)$ \\
\hline Number of sport disciplines & 61 & 59 & 63 & 42 & 16 & 75 & 21 \\
\hline Experience (years) & $7.81(4.13)$ & $8.09(4.35)$ & $7.78(4.43)$ & $7.33(3.85)$ & $3.91(2.72)$ & $9.62(7.78)$ & $10.1(9.13)$ \\
\hline \multicolumn{8}{|l|}{ Competitive Level: } \\
\hline Recreational & 210 & 137 & 130 & 34 & 17 & 150 & 20 \\
\hline Club & 273 & 122 & 138 & 32 & 9 & 123 & 16 \\
\hline National & 210 & 71 & 81 & 24 & 1 & 32 & 1 \\
\hline International & 104 & 50 & 50 & 17 & 0 & 13 & 3 \\
\hline
\end{tabular}

$N$ number of participants; Parentheses present the standard deviation. $\mathrm{T} 1=$ first measurement, $\mathrm{T} 2=$ second measurement (re-test)

reported potential problems, e.g., item length or reading level difficulty. Based on this input items were retained, modified, or deleted. An agreement of $80 \%$ among the investigators was required to retain an item in its original form.

\section{Analysis}

We performed principal component analysis (PCA) using SPSS 23.0 (Armonk, NY) with an direct oblimin rotation (Osborne and Costello 2009). To ensure minimal ambiguity between factors, criteria for an acceptable factor solution were: minimum eigenvalue of one and the minimum of three items loading on each factor (Tabachnick and Fidell 2007). The criteria for item exclusion were: a loading below .50 and cross-loading greater than .32 on any other factor (Osborne and Costello 2009). Listwise deletion was used for missing data.

To support the content validity we analyzed the experts' answers. To establish the reliability of agreement between raters we calculated Fleiss'k (Fleiss et al. 1969). This is a statistical measure for a fixed number of raters and categorical ratings with an inter-rater reliability coefficient $k>.80$ interpreted as an almost perfect agreement (Fleiss et al. 2013).

\section{Results and Discussion}

The analysis identified 13 principal components that accounted for $55.7 \%$ of the variance. However, the scale failed to provide a rotated solution suggesting that 13 factors were unnecessary (Tabachnick and Fidell 2007). Scree plot inspection revealed four meaningful components in line with the conceptual framework. Direct oblimin rotation produced a 4 factor solution with 25 items, accounting for $47.71 \%$ of the variance. The items had moderate communalities ranging from .32-.65. The mean item score was 3.73 with higher scores representing greater mental training intensity.

The 24-itemquestionnaire showed satisfactory internal consistency (Cronbach's $\alpha=.86$ ) with item-total correlations ranging from .316 to .539 . Based on items that remained in the instrument we relabelled the third subscale as interpersonal skills (previous personal development skills). The interpersonal skills were defined as the ability to interact effectively with others (Vealey 2007). Cronbach's $\alpha$ s showed acceptable internal consistency for each of the four subscales (Kline 2005):foundations skills ( 5 items) $\alpha=.73$, performance skills(7 items) $\alpha=.81$, interpersonal skills(5 items) $\alpha=.76$, and mental techniques( 7 items $) \alpha=.80$.

\section{Content Validity}

Experts' agreement supported the four-factor model, $\mathrm{K}=.81$ (95\% CI, .74 to .87), $p<.001$.Twentythree items received unanimous endorsement from the six reviewers, i.e., more than $80 \%$ of experts believed the item tapped the intended construct, did not correspond to another subscale, and was worded clearly. However, experts reported problems with several items in the mental techniques subscale. Some of the items included statements about using mental techniques during performance. We removed "performance statements" and retained items with the more general meaning. For instance, "During the performance I talk to myself to regulate my own thoughts, emotions, or arousal" was modified into "I talk to myself to regulate my own thoughts, emotions, and arousal."Finally, we removed one item from the mental techniques scale which did not meet the prior requirements. 


\section{Study2}

The purpose of Study 2 was to re-examine the factor structure of the 23-item SMTQ developed in Study 1using another sample.

\section{Material and Methods}

\section{Participants}

Participants were 405 athletes who completed questionnaires in groups of 10-20 individuals $(N=250)$ recruited from local sport clubs and University students from the Faculty of Physical Education, or via a web-based survey $(N=155)$ (For details, see Table 2). Written informed consent was obtained from each participant.

\section{Measures}

The 23-item inventory for mental training was used with the same response format. Other measures were identical to those used in Study 1.

\section{Results and Discussion}

Analytical strategy was the same as in Study 1. Direct oblimin rotation produced a 5-componet solution with 23 items accounting for $54.9 \%$ of the variance. Based on the previously adopted criteria, three items were removed from the subsequent analysis. The items had moderate communalities ranging from .43 to .75 . The mean item score was 3.70. Based on PCA results we divided mental techniques into two subscales: selftalk (inner dialogue)and mental imagery (using images for situation rehearsal). It supported previous findings which have shown that these particular skills are effective and frequently used (Hatzigeorgiadis et al. 2014; MacIntyre et al. 2013).

The 20-item SMTQ was internally consistent with Cronbach's $\alpha=.83$ andacceptable internal consistency for subscales: foundations skills( 4 items) $\alpha=.73$, performance skills (6 items) $\alpha=.79$, interpersonal skills (4 items) $\alpha=.75$, mental imagery ( 3 items) $\alpha=.70$, and self-talk ( 3 items) $\alpha=.72$. The final 20 items and their loadings are reported in Table 3.

\section{Study 3}

The aim of Study 3 was to use structural equation modeling (SEM) to validate findings from Study 2. We hypothesized that athletes with a higher competitive level would display higher mental preparation level compared with those competing at a lower level. To evaluate the test-retest reliability, the SMTQ was administered over a 3-weeks period.

\section{Material and Methods}

\section{Participants}

Participants were 429 athletes who completed questionnaires in groups of 10-20 individuals $(N=220)$ recruited from local sport clubs and University students from the Faculty of Physical Education, or via a web-based survey $(N=209)$ (Table 2). Written informed consent was obtained from each participant.

\section{Measures and Procedure}

The 20-item inventory for mental training was used. Other measures and procedures were identical to those in Study 1 .

\section{Analysis}

We performed structural equation modeling with mPlus 7.2 with the MLM estimator (Muthén and Muthén 2012). Following guidelines for evaluation of model fit $(\mathrm{Hu}$ and Bentler 1999), we calculated Standardized Root Mean Squared Residual (SRMR, values $<.08$ indicating good fit) supplementing it with Room Mean Squared Error of Approximation (RMSEA, values $<.06$ indicating good fit).An item may be removed if the fit statistics are inadequate and the item fails to meet one or more of the following criteria: large standardized residuals $(>2.00)$,modification indices suggesting that the error term of an item correlated with that of another item, low factor loading (<.40; Mullan et al. 1997), or cross-loading on an unintended latent factor (Hair 2010).

Next, we examined the reliability of the SMTQ in two ways: Cronbach's $\alpha$ and test-rest reliability. Interclass correlation coefficients were calculated using a two-way mixed effect model to establish test-retest reliability.

To test the construct and concurrent validity the samples from Study 2 and Study 3 were combined, totalling the number of 835 participants. To compare differences between the high and low-level, female and male athletes, $t$ tests for independent samples were performed on each of the five factors and the overall score. For the purpose of criterion validity analyses, the participants were grouped into the following categories:

Competition Level Among the participants, 252 high-level and 427 low-level athletes were identified. In line with previous research (Eton et al. 1998; Roberts et al. 2008), the highlevel athletes were defined as those who participated in their sport at a national and international level, and low-level athletes were those who participated in their sport at a recreational or club level. To ensure that each sport was represented equally in each group, participants were matched for sport type across the two groups. Where sports were not matched, the respective data were deleted from the sample. This resulted in a sample of 326 sport-matched participants, 163 per group. 
Table 3 SMTQ items and factor loadings for five-factor solution (Study 2)

\begin{tabular}{|c|c|c|c|c|}
\hline & $\begin{array}{l}\text { foundation } \\
\text { skills }\end{array}$ & $\begin{array}{l}\text { performance } \\
\text { skills }\end{array}$ & $\begin{array}{l}\text { interpersonal } \\
\text { skills }\end{array}$ & $\begin{array}{l}\text { mental } \\
\text { imagery }\end{array}$ \\
\hline
\end{tabular}

3. I have a high level of self-confidence that makes me believe I can achieve anything I put $\quad-.756$ my mind to.

14. I have an unshakable belief in my athletic ability. $\quad-.755$

10. I know my own value, my strengths and weaknesses, and I plan how to improve them. - -.673

7. I am able to "bounce back" and overcome any failure. It does not discourage me from -.641 further action.

5. When I am under pressure during a competition I'm able to relax physically and mentally, so that I am ready to perform.

19. I am able to concentrate my attention on my performance and maintain it during it's duration, and in case of any disruption, I can quickly refocus

1. I can control my emotions when I am under pressure.

.729

.728

.691

.627

12. Whenever I lose myself-control during a competition, I can regain control of my own actions in the right moment.

16. I can relax, and reduce my arousal level during competition if the situation requires so.

.603

8. During a competition I am able to adapt quickly to changes in performance demands and to distracting factors.

11. I accept my role in the group and I see it clearly.

15. I understand my role, and the role of others on my team and how it all fits into the greater system.

4. I understand and follow the rules established in training.

18. I am able to communicate effectively with my team and staff during the competition.

6. I use self-talk to help myself overcome difficult times.

13. I talk to myself to regulate my own thoughts, emotions and arousal.

17. I use mental imagery to control my own emotions.

20. Before the start of competition I visualize my performance going exactly the way I want it to look like during the real competition.

9. During preparation for the competition I create real and accurate "inner films," planning possible obstacles and feeling sensations associated with the actual situation to come
$-.763$

$-.762$

$-.716$

$-.624$

$-.762$

$-.733$

$-.695$
Gender In the sample, 368 female and 466 male athletes were identified. To ensure that each gender was represented equally in each group, participants were matched for sport type and competition level across the male and female groups. Where competition level and sport discipline were not matched, the respective data were deleted from the sample. This resulted in a sample of 376 sport-matched participants, 188 per group.

Pearson's $r$ correlations were used to examine the second hypothesis regarding evidence for concurrent validity.

\section{Results and Discussion}

\section{Structural Equation Modeling}

Due to of the partial conceptual overlap between mental skills and mental techniques, a five-factor model was tested (Fig. 1). The hypothesized second-order solution with two scales: mental skills (foundation, performance, and interpersonal skills) and mental techniques (self-talk and mental imagery) demonstrated an adequate fit to the data, SRMR $=.048$, RMSEA $=.042,90 \%$ CI $[.034 ; .050]$. Inspection of the standardized factor loadings (from .48 to.86), modification indices, and standardized residuals revealed all values were within acceptable limits (Hair 2010). Consequently, each item meaningfully contributed to its intended subscale.

\section{Reliability}

Adequate internal reliability was demonstrated for the model $(\mathrm{Cr}=.86)$ and all five subscales with Cronbach's $\alpha$ values (foundations skills $\alpha=.75$, performance skills $\alpha=.81$, interpersonal skills $\alpha=.78$, mental imagery $\alpha=.75$, self-talk $\alpha=.76$ ) with item-total correlations ranging from .30 to .55 . All results were above the acceptable cut off criterion ( $\alpha \geq .70$; Kline 2005).

After three weeks, an adequate test-retest reliability was demonstrated for the model $(\alpha=.89)$ and all five subscales with $\alpha$ foundations skills $\alpha=.80$, performance skills $\alpha=.83$, interpersonal skills $\alpha=.84$, mental imagery $\alpha=.81$, self-talk $\alpha=.72$ ). All results were above the acceptable cut off criterion ( $\alpha \geq$.70; Kline 2005). These results demonstrated test-retest reliability of the SMTQ over a 3-week period. 
Fig. 1 The hierarchical structure of mental training in sports. Confirmatory factor analysis with standardized coefficients. Note. Numbers next to the shortcut of the scales correspond to order each items within the scales. Numbers in parenthesis correspond to order each items within the questionnaire

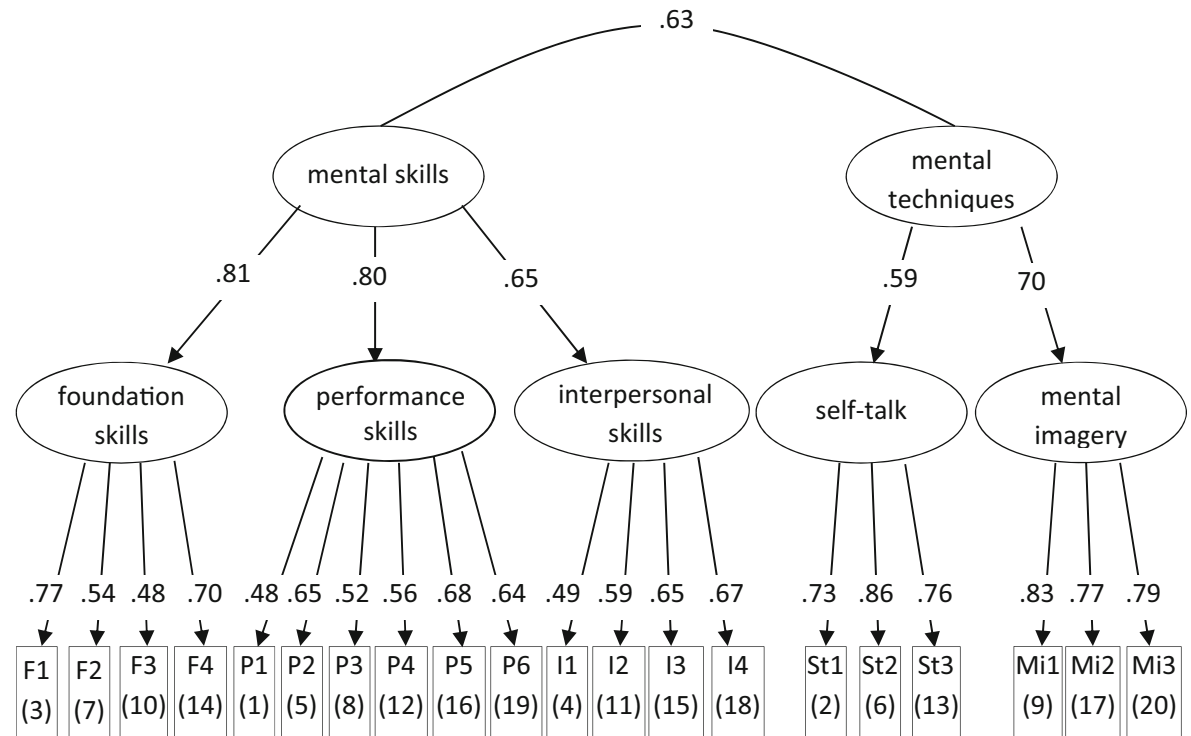

\section{Criterion Validity}

High-level athletes had higher levels of foundation, performance, interpersonal skills and scored higher on mental imagery and self-talk scales compared to low-level athletes (Table 4). Male athletes scored higher on foundations skills, performance skills, and overall score compared to female athletes (Table 4).

The purpose of construct validity analyses was to see if the SMTQ was able to distinguish between groups of athletes based on previous research suggesting that certain athlete characteristics such as competitive level or gender influence mental training components (Durand-Bush et al. 2001; Gould et al. 2002; Roberts et al. 2008; Thomas et al. 1999; Zourbanos et al. 2009). It was hypothesized that athletes of a higher competitive level would display higher mental training levels compared to lower competitive level athletes. Our findings supported this hypothesis. We also observed meaningful differences between male and female athletes.

\section{Study 4}

The aim of this study was to develop the English version of the SMTQ. First, the scale was translated and evaluated qualitatively. Second, we established the convergence between the translation and the original version.

\section{Material and Methods}

\section{Participants}

Participants were 54 English philology students (Table 2).Written informed consent was obtained from each participant.

\section{Measures}

The measures were identical to those used in Study 1.Sport Mental Training Questionnaire-Polish and English (SMTQPL \& SMTQ-ENG) were used.

\section{Procedures and Analysis}

The original scale was independently translated into English by mental training experts fluent in English. The four versions were discussed and merged into one in line with the consensual approach. A back translation was prepared by an independent translator. The back translation compared against the original further supported validity of the translation. Subsequently, we used the bilingual answers method for testing the convergence between translation and the original. Half of the participants completed the SMTQ-ENG as the first scale. The $r$-Person correlation of the total scores for both scales and Student's $t$ test were computed with SPSS 23.00 (Armonk, NY).

\section{Results and Discussion}

Both language version had comparable internal consistency: SMTQ-PL with $\alpha=.85$ and SMTQ-ENG with $\alpha=.84$. Supporting the scales convergence, there was no difference between the overall score on the SMTQ-ENG $(M=67.38$, $S D=9.93)$ and the SMTQ-PL $(M=67.14, S D=10.29), t$ $(106)=0.12, p=.90, d=0.02$, and none of the scales: foundation skills, $t(106)=-0.22, p=.83, d=-0.04$; performance skills, $t(106)=-.10, p=.92, d=-0.02$; ;interpersonal skills, $t$ $(106)=.48, p=.63, \mathrm{~d}=0.09$; self-talk, $t(106)=-.09, p=.92$, $d=0.02$; and mental imagery, $t(106)=.49, p=.62, d=0.09$. The convergence of both questionnaires was excellent for the 
overall score $r=.97, p<.001$,foundation skills, $r=.96$, $p<.001$; performance skills, $r=.96, p<.001$,interpersonal skills, $r=.96, p<.001$; self-talk, $r=.92, p<.001$; and mental imagery, $r=.92, p<.001$. The obtained result showed that the adaptation was satisfactory.

\section{Study 5}

Study 5 was conducted to confirm the construct validity of English version of the Questionnaire by testing its factorial structure against the underlying theory

\section{Material and Methods}

\section{Participants}

Participants were 330 athletes from 48 countries who completed questionnaires in groups of 10-20 individuals $(N=162)$ recruited from local sport clubs and local Universities (international exchange students who studied in English), or via a web-based survey $(N=168)$ (Table 2).As language skills in this group vary substantially, we excluded students who reported in a control question that they had language problems while completing the survey.

Written informed consent was obtained from each participant.

\section{Measures and Procedures}

The measures and procedures were the same as in Study2. The English version of the SMTQ was used. We also added a question about the country of origin.

\section{Analysis}

Statistical strategy was identical to that used in study 3.For the purpose of criterion validity, participants were grouped by category based on their a) competition level(from this sample, 45 high-level and 273 low-level athletes were identified, following the same procedure as in study 3 the sample resulted in 74 sport-matched participants, 37 per group), b) gender(from this sample, 172 female and 157 male athletes were identified; following the same procedure as in study 3 the sample resulted in 82 sport-matched participants, i.e., 41 per group).

\section{Results and Discussion}

\section{Factorial Structure}

We excluded four students who reported in a control question that they had language problems.
The hypothesized model identified in Study 3 demonstrated an adequate fit to the data in Study 5, SRMR $=.049$, RMSEA $=.042,90 \%$ CI $[.032 ; .052]$. Inspection of the standardized factor loadings (ranging from .48 to .86), modification indices, and standardized residuals revealed all values were within acceptable limits and no offending estimates existed (Hair 2010).

\section{Reliability}

Adequate reliability was demonstrated for the model $(\mathrm{Cr}=.84)$ and performance skills $\alpha=.78$, interpersonal skills $\alpha=.72$, mental imagery $\alpha=.70$, and self-talk $\alpha=.85$ ) with item-total correlations ranging from .23 to .52 . Cronbach's $\alpha$ reliability analysis was lower for foundations skills $(\alpha=.60)$.However, based on previous findings, we propose that the foundations skills subscale should retain for further examination in future studies.

Forty participants of Study 5 (Table 2) were asked to complete the SMTQ for the second time after three weeks. Testretest reliability was demonstrated for the model $(\mathrm{Cr}=.83)$ and all five subscales with Cronbach's $\alpha$ values (foundations skills $\alpha=.64$, performance skills $\alpha=.75$, interpersonal skills $\alpha=.73$, mental imagery $\alpha=.67$, self-talk $=\alpha$ .86).Consequently, results demonstrate test-retest reliability of the SMTQ over a 3-weeks period.

\section{Criterion Validity}

We found that high level athletes had higher foundation skills, performance skills, and the overall level of mental training level compare to low level athletes (Table 4). There were no significant differences for interpersonal skills, self-talk, and mental imagery. Furthermore, female athletes scored higher on interpersonal skills, self-talk, and mental imagery and lower on foundational and performance skills. These analyses partly replicated findings from Study 3.

\section{General Discussion}

Training of specific mental skills and techniques facilitates success in sports (Gould et al. 2002).Despite several studies that examined mental skills and techniques (see Gardner and Moore 2006 for a review), there is still little consensus regarding the most robust and parsimonious structure of mental training components. Understanding core elements of mental training is critical for successful psychological evaluation and preparation to athletic performance. Building upon prior models of mental training in sport (Vealey 2007) and available psychometric instruments we developed an integrative multidimensional model of mental skills and techniques used in sports. The conceptual and psychometric analyses revealed the components that are essential to mental training as well 
Table 4 Criterion validity on the 20-item SMTQ-PL\& SMTQ-ENG

\begin{tabular}{|c|c|c|c|c|c|c|c|c|}
\hline Characteristics & Low Level & High Level & $t$ & Effect size $(d)$ & Female & Male & $t$ & Effect size $(d)$ \\
\hline \multicolumn{9}{|l|}{ Polish version } \\
\hline $\mathrm{N}$ & 163 & 163 & & & 188 & 188 & & \\
\hline Foundations skills & $14,85(2,61)$ & $15,53(2,75)$ & $2.29^{*}$ & 0.25 & $14,60(2,90)$ & $15,70(2,65)$ & $3.82^{* * *}$ & 0.31 \\
\hline Performance skills & $20,61(3,50)$ & $21,57(4,02)$ & $2.31^{*}$ & 0.25 & $20,56(3,63)$ & $21,82(3,81)$ & $43.27^{* * * *}$ & 0.33 \\
\hline Interpersonal skills & $15,82(2,52)$ & $16,79(2,64)$ & $3.38^{* * * *}$ & 0.38 & $16,38(2,46)$ & $16,39(2,74)$ & 0.2 & 0.01 \\
\hline Self-talk & $11,26(2,59)$ & $11,90(2,47)$ & $2.30^{*}$ & 0.25 & $11,46(2,65)$ & $11,43(2,74)$ & 0.12 & 0.01 \\
\hline Mental imagery & $10,18(2,51)$ & $11,37(2,59)$ & $4.19^{* * *}$ & 0.46 & $10,5(2,55)$ & $10,74(2,74)$ & 0.88 & 0.09 \\
\hline Overall score & $72,72(7,60)$ & $77,17(9,71)$ & $4.60^{* * * *}$ & 0.51 & $73,51(9,47)$ & $76,07(9,47)$ & $2.65^{* * *}$ & 0.27 \\
\hline \multicolumn{9}{|l|}{ English version } \\
\hline $\mathrm{N}$ & 37 & 37 & & & 41 & 41 & & \\
\hline Foundations skills & $13,92(2,89)$ & $15,81(2,41)$ & $3.06^{* *}$ & 0.71 & $13,87(2,86)$ & $14,66(2,41)$ & 1.39 & 0.31 \\
\hline Performance skills & $20,98(3,35)$ & $23,57(3,66)$ & $3.19^{* * *}$ & 0.74 & $20,17(3,16)$ & $21,09(4,06)$ & 1.15 & 0.25 \\
\hline Interpersonal skills & $16,68(2,30)$ & $17,35(2,08)$ & 1.33 & 0.31 & $16,41(2,17)$ & $15,60(2,88)$ & 1.42 & 0.31 \\
\hline Self-talk & $9,81(3,08)$ & $11,05(2,86)$ & 1.79 & 0.41 & $11,27(2,50)$ & $10,24(2,39)$ & 1.63 & 0.36 \\
\hline Mental imagery & $9,92(2,51)$ & $10,82(2,72)$ & 1.58 & 0.37 & $10,68(2,78)$ & $10,64(2,78)$ & 1.32 & 0.09 \\
\hline Overall score & $71,30(8,98)$ & $78,68(9,09)$ & $3.51^{* *}$ & 0.82 & $72,41(8,77)$ & $72,07(10,27)$ & 0.16 & 0.03 \\
\hline
\end{tabular}

${ }^{*} p<.05,{ }^{* *} p<.01,{ }^{* * *} p<.001$. Mean differences calculated by tests for independent samples, degree of freedom were 324,374, 72, 80 for the Polish version high vs low level athletes, female vs male, English version high vs low level athletes, female vs male

as their most parsimonious structure. More specifically, we identified the most viable factors, i.e., foundation skills, performance skills, interpersonal skills and mental techniques. This corroborates and extends previous conceptualizations (Vealey 2007). Furthermore, we provided new evidence that self-talk and mental imagery can be considered the most distinguished mental techniques used by athletes (Hatzigeorgiadis et al. 2014; MacIntyre et al. 2013).Finally, our analyses supported a hierarchical structure of mental skills and techniques with two overarching separate factors comprising skills (foundation, performance, and interpersonal) and techniques (self-talk and mental imagery). This hierarchical order is helpful to emphasize that skills and techniques are two separate targets that should be addressed in psychological preparation for an athletic performance.

Our multistep work resulted in a new psychometric instrument that advances the measurement of mental training components. This work provided a brief questionnaire with strong psychometric properties such as high internal consistency, high temporal stability, supported construct validity, and equivalence of two language versions of the questionnaire. Moreover, we provided evidence for criterion validity of the SMTQ scores. For instance, more experienced athletes had significantly higher mental training skills and techniques compared to lower-level athletes; a finding in line with previous studies (Gould et al. 2002; Thomas et al. 1999). This is because high-level athletes engage in more psychologically demanding practice and performance with more frequent opportunities to craft greater mental preparation. Gender differences were also observed. Male athletes scored significantly higher on the foundation and performance scale in line with previous research (McGrane et al. 2016; Smirniotou et al. 2009; Hammermeister and Burton 2004). These results indicate specific weaker points that should be targeted to minimize gender differences.

Using questionnaires that provide maximum information and place minimal burden on the athletes and at the same time are valid and reliable is critical in sports science so that the assessment does not interfere with the training process. Thus, our empirical findings suggest that the final versions of SMTQ might be an optimal choice for researchers and practitioners that are interested in obtaining brief data that cover the most critical aspects of mental training. Yet, some other instruments can be considered a better choice to pinpoint specific aspects of mental training.

One strength of this project is that it resulted in a questionnaire that is already available in two language versions: English and a Central European language. This is likely to facilitate cross-cultural research that is currently sparse and still needed in sports psychology after decades of calling for more systematic work on culture in sport (Duda and Allison 1990). For instance, the population of Poland compared to USA is less individualistic and indulging but more prone to uncertainty avoidance (Hofstede et al. 2010). It would be a worthwhile to research how such cultural differences moderate mental training preferences, practice, and outcomes. Cross-cultural perspectives in sports psychology has been still considered a new line of research focused on a contextualized approach towards humans and their 
performance (Blodgett et al. 2015). Moreover, within the cross-cultural approach, there is little research focused on Central and Eastern European populations with the majority of studies focused on other race or ethnic issues reflecting cultural identity.

Several study limitations require consideration. First, some conceptual problems with the measurement of components of mental training emerged. The results of Study 1 confirmed some of the problems identified by other authors (Birrer et al. 2012; Vealey 2007), i.e., the distinction between mental skills and mental techniques. Second, SMTQ can fall short for some more sophisticated research questions or practical applications. For example, the instrument does not differentiate between athletes' use of attentional focus as well as motivational and instructional self-talk (Zourbanos et al. 2009). Neither does it distinguish between the use of internal, external, or kinaesthetic imagery (Roberts et al. 2008). As a result of adopted inclusion criteria, SMTQ also lacks items that concern goal-setting, which has been identified by some researchers as one of the most popular mental technique used by athletes (Brewer 2009). Moreover, we have not compared our measure with any already existing questionnaire seeking to understand whether this new questionnaire accounts for additional variance in sport-related outcomes. Finally, the results are based on cross-sectional and self-report data. Further studies might use prospective designs and observational measures to ascertain that SMTQ predicts real-life preparatory actions and sport performance outcomes.

Acknowledgements We express our gratitude to Barbara Sondergaard, Kathrine Zabłocka, and Michael Kosakowski, who contributed to the translation. The authors also offer sincere thanks to all coaches, lecturers, psychologist, and friends who provided very helpful comments, access for research groups, and helped with promotion of the study.

\section{Compliance with Ethical Standards}

Founding This research did not receive any specific grant from funding agencies in the public, commercial, or not-for-profit sectors.

Ethical Approval All procedures performed in studies involving human participants were in accordance with the ethical standards of the institutional and/or national research committee and with the 1964 Helsinki declaration and its later amendments or comparable ethical standards.

Informed Consent Informed consent was obtained from all individual participants included in the study.

Conflict of Interest Author A declares that he has no conflict of interest. Author B declares that he has no conflict of interest. Author C declares that he has no conflict of interest. Author D declares that he has no conflict of interest. Author E declares that he has no conflict of interest.
Open Access This article is distributed under the terms of the Creative Commons Attribution 4.0 International License (http:// creativecommons.org/licenses/by/4.0/), which permits unrestricted use, distribution, and reproduction in any medium, provided you give appropriate credit to the original author(s) and the source, provide a link to the Creative Commons license, and indicate if changes were made.

\section{References}

Albrecht, R. R., \& Feltz, D. L. (1987). Generality and specificity of attention related to competitive anxiety and sport performance. Journal of Sport Psychology, 9, 1-248.

Anshel, M., \& Anderson, D. (2002). Coping with acute stress in sport: Linking athletes' coping style, coping strategies, affect, and motor performance. Anxiety, Stress \& Coping, 15, 193209.

Beckmann, J., \& Kellmann, M. (2003). Procedures and principles of sport psychological assessment. The Sport Psychologist, 17, 338-350.

Birrer, D., \& Morgan, G. (2010). Psychological skills training as a way to enhance an athlete's performance in high-intensity sports. Scandinavian Journal of Medicine \& Science in Sports, 20, 78-87.

Birrer, D., Röthlin, P., \& Morgan, G. (2012). Mindfulness to enhance athletic performance: Theoretical considerations and possible impact mechanisms. Mindfulness, 3, 235-246.

Blodgett, A. T., Schinke, R. J., McGannon, K. R., \& Fisher, L. A. (2015). Cultural sport psychology research: Conceptions, evolutions, and forecasts. International Review of Sport and Exercise Psychology, 8, 24-43.

Brewer, B. W. (2009). Introduction. In B. W. Brewer (Ed.), Handbook of sports Medicine and science (pp. 1-6). Sport Psychology: John Wiley \& Sons.

Bull, S. J., Albinson, J. G., \& Shambrook, C. J. (1996). The mental game plan: Getting psyched for sport. Eastbourne: Sports Dynamics.

Duda, J. L., \& Allison, M. T. (1990). Cross-cultural analysis in exercise and sport psychology: A void in the field. Journal of Sport \& Exercise Psychology, 12, 114-131.

Dunn, J. G., Bouffard, M., \& Rogers, W. T. (1999). Assessing item content-relevance in sport psychology scale-construction research: Issues and recommendations. Measurement in Physical Education and Exercise Science, 3, 15-36.

Durand-Bush, N., Salmela, J. H., \& Green-Demers, I. (2001). The Ottawa mental skills assessment tool (OMSAT-3). The Sport Psychologist, $15,1-19$.

Edwards, D. J., \& Steyn, B. J. M. (2011). Establishment of norms for the Bull's mental skills questionnaire in south African university students: An exploratory study. African Journal for Physical, Health Education, Recreation and Dance, 17, 526-534.

Eton, D. T., Gilner, F. H., \& Munz, D. C. (1998). The measurement of imagery vividness: A test of the reliability and validity of the vividness of visual imagery questionnaire and the vividness of movement imagery questionnaire. Journal of Mental Imagery, 22, 125-136.

Fleiss, J. L., Cohen, J., \& Everitt, B. S. (1969). Large sample standard errors of kappa and weighted kappa. Psychological Bulletin, 72, 323.

Fleiss, J. L., Levin, B., \& Paik, M. C. (2013). Statistical methods for rates and proportions. New York: John Wiley \& Sons.

Gardner, F., \& Moore, Z. (2006). Clinical sport psychology. Human kinetics.

Gentili, R., Han, C. E., Schweighofer, N., \& Papaxanthis, C. (2010). Motor learning without doing: Trial-by-trial improvement in motor 
performance during mental training. Journal of Neurophysiology, 104, 774-783.

Golby, J., Sheard, M., \& Van Wersch, A. (2007). Evaluating the factor structure of the psychological performance inventory. Perceptual and Motor Skills, 105, 309-325.

Gould, D., Guinan, D., Greenleaf, C., Medbery, R., \& Peterson, K. (1999). Factors affecting Olympic performance: Perceptions of athletes and coaches from more and less successful teams. The Sport Psychologist, 13, 371-394.

Gould, D., Dieffenbach, K., \& Moffett, A. (2002). Psychological characteristics and their development in Olympic champions. Journal of Applied Sport Psychology, 14, 172-204.

Hair, J. F. (2010). Multivariate data analysis. Pearson College Division.

Hammermeister, J., \& Burton, D. (2004). Gender differences in coping with endurance sport stress: Are men from Mars and women from Venus? Journal of Sport Behaviour, 27, 148-164.

Hardy, L., Roberts, R., Thomas, P. R., \& Murphy, S. M. (2010). Test of performance strategies (TOPS): Instrument refinement using confirmatory factor analysis. Psychology of Sport and Exercise, 11, 27-35.

Hatzigeorgiadis, A., Theodorakis, Y., \& Zourbanos, N. (2004). Self-talk in the swimming pool: The effects of self-talk on thought content and performance on water polo tasks. Journal of Applied Sport Psychology, 16, 138-150.

Hatzigeorgiadis, A., Zourbanos, N., Goltsios, C., \& Theodorakis, Y. (2008). Investigating the functions of self-talk: The effects of motivational self-talk on self-efficacy and performance in young tennis players. The Sports Psychologist, 22, 458-471.

Hatzigeorgiadis, A., Zourbanos, N., Mpoumpaki, S., \& Theodorakis, Y. (2009). Mechanisms underlying the self-talk-performance relationship: The effects of motivational self-talk on self-confidence and anxiety. Psychology of Sport and Exercise, 10, 186-192.

Hatzigeorgiadis, A., Galanis, E., Zourbanos, N., \& Theodorakis, Y. (2014). Self-talk and competitive sport performance. Journal of Applied Sport Psychology, 26, 82-95.

Hill, D. M., Hanton, S., Matthews, N., \& Fleming, S. (2010). A qualitative exploration of choking in elite golf. Journal of Clinical Sport Psychology, 4, 221-240.

Hofstede, G., Hofstede, G. J., \& Minkov, M. (2010). Cultures and organizations: Software of the mind. Revised and expanded. McGrawHill, New York.

Hu, L. T., \& Bentler, P. M. (1999). Cutoff criteria for fit indexes in covariance structure analysis: Conventional criteria versus new alternatives. Structural equation modeling: a multidisciplinary journal, 6, 1-55.

Kline, T. J. (2005). Psychological testing: A practical approach to design and evaluation. Sage Publications.

Lane, A. M., Beedie, C. J., Devonport, T. J., \& Stanley, D. M. (2011). Instrumental emotion regulation in sport: Relationships between beliefs about emotion and emotion regulation strategies used by athletes. Scandinavian Journal of Medicine\& Science in Sports, 21, e445-e451.

Loehr, J. E. (1986). Mental toughness training for sports: Achieving athletic excellence. Penguin Books.

Lutz, A., Slagter, H. A., Rawlings, N. B., Francis, A. D., Greischar, L. L., \& Davidson, R. J. (2009). Mental training enhances attentional stability: Neural and behavioral evidence. Journal of Neuroscience, 29, 13418-13427.

MacIntyre, T., Moran, A., Collet, C., Guillot, A., Campbell, M., Matthews, J., \& Mahoney, C. (2013). The BASES expert statement on the use of mental imagery in sport, exercise and rehabilitation contexts. The Sport and Exercise Scientist, 38, 10-11.

Mahoney, M. J., Gabriel, T. J., \& Perkins, T. S. (1987). Psychological skills and exceptional athletic performance. The Sport Psychologist, $1,181-199$.
McAuley, E. (1985). Modelling and self-efficacy: A test of Bandura's model. Journal of Sport Psychology, 7, 283-295.

McGrane, B., Belton, S., Powell, D., Woods, C. B., \& Issartel, J. (2016). Physical self-confidence levels of adolescents: Scale reliability and validity. Journal of Science and Medicine in Sport, 19, 563-567.

Mesagno, C., Harvey, J. T., \& Janelle, C. M. (2012). Choking under pressure: The role of fear of negative evaluation. Psychology of Sport and Exercise, 13, 60-68.

Michie, S., Richardson, M., Johnston, M., Abraham, C., Francis, J., Hardeman, W., et al. (2013). The behavior change technique taxonomy (v1) of 93 hierarchically clustered techniques: Building an international consensus for the reporting of behavior change interventions. Annals of Behavioral Medicine, 46, 81-95.

Mullan, E., Markland, D., \& Ingledew, D. K. (1997). A graded conceptualisation of self-determination in the regulation of exercise behaviour: Development of a measure using confirmatory factor analytic procedures. Personality and Individual Differences, 23, 745-752.

Muthén, L. K., \& Muthén, B. O. (2012). Mplus statistical modeling software: Release 7.0. Los Angeles, CA: Muthén \& Muthén.

Netemeyer, R. G., Bearden, W. O., \& Sharma, S. (2003). Scaling procedures: Issues and applications. Sage Publications.

Nideffer, R. M. (1976). Test of attentional and interpersonal style. Journal of Personality and Social Psychology, 34, 394-404.

Orlick, T. (1992). The psychology of personal excellence. Contemporary thought on performance enhancement, 1, 109-122.

Osborne, J. W., \& Costello, A. B. (2009). Best practices in exploratory factor analysis: Four recommendations for getting the most from your analysis. Pan-Pacific Management Review, 12, 131-146.

Roberts, R., Callow, N., Hardy, L., Markland, D., \& Bringer, J. (2008). Movement imagery ability: Development and assessment of a revised version of the vividness of movement imagery questionnaire. Journal of Sport \& Exercise Psychology, 30, 200-221.

Smirniotou, A., Katsikas, C., \& Argeitaki, P. (2009). Performance strategies of Greek track and field athletes gender and level differences. Biology of Exercise, 5, 29-38.

Smith, R. E., Schutz, R. W., Smoll, F. L., \& Ptacek, J. T. (1995). Development and validation of a multidimensional measure of sport-specific psychological skills: The Athletic Coping Skills Inventory-28. Journal of Sport and Exercise Psychology, 17, 379398.

Snauwaert, E. (2001, May). A psychometric evaluation of Bull's mental skills questionnaire: A study on Flemish athletes. Proceedings of the 10th World Congress of Sport Psychology, Greece,5, 23-25.

Tabachnick, B. G., \& Fidell, L. S. (2007). Using multivariate statistics, 5th. Needham Height: Allyn \& Bacon.

Thelwell, R., Greenlees, I., \& Weston, N. (2010). Examining the use of psychological skills throughout soccer performance. Journal of Sport Behaviour, 33, 109-127.

Thomas, P. R., Murphy, S. M., \& Hardy, L. (1999). Test of performance strategies: Development and preliminary validation of a comprehensive measure of athletes' psychological skills. Journal of Sports Sciences, 17, 697-711.

Tkachuk, G., Leslie-Toogood, A., \& Martin, G. L. (2003). Behavioural assessment in sport psychology. The Sport Psychologist, 17, 104 117.

Tutko, T. A., Lyon, L. P., \& Ogilvie, B. C. (1969). Athletic motivation inventory. San Jose: Institute for the Study of Athletic Motivation.

Uneståhl, L. E. (2015). 50 years with integrated mental training. Swedish Journal of Sport Research, 82-108.

Vealey, R. S. (2007). Mental skills training in sport. In: Editors (eds.) Handbook of Sport Psychology, Third Edition, pp 285-309.

Velentzas, K., Heinen, T., \& Schack, T. (2011). Routine integration strategies and their effects on volleyball serve performance and players' 
movement mental representation. Journal of Applied Sport Psychology, 23, 209-222.

Weinberg, R. S., \& Gould, D. (2015). Foundations of sport and exercise psychology, Sixth Edition. Human Kinetics.

Williams, S. E., \& Cumming, J. (2011). Measuring athlete imagery ability: The sport imagery ability questionnaire. Journal of Sport and Exercise Psychology, 33, 416-440.
Worthington, R. L., \& Whittaker, T. A. (2006). Scale development research: A content analysis and recommendations for best practices. The Counseling Psychologist, 34, 806-838.

Zourbanos, N., Hatzigeorgiadis, A., Chroni, S., Theodorakis, Y., \& Papaioannou, A. (2009). Automatic self-talk questionnaire for sports (ASTQS): Development and preliminary validation of a measure identifying the structure of athletes' self-talk. The Sport Psychologist, 23, 233-251. 